\title{
Association of antibiotic resistance with SHV-12 extended-spectrum $\beta$-lactamase in Enterobacter cloacae
}

\author{
JUN LIU ${ }^{1}$, GUO-MING LI ${ }^{1}$, LI-YAO LIN ${ }^{2}$, XIA-LEI WU ${ }^{3}$, SHAO-LONG HUANG $^{4}$, \\ $\mathrm{YONG} \mathrm{ZHOU}^{4}$ and $\mathrm{ZU}-\mathrm{GUO} \mathrm{ZHAO}^{1}$
}

\author{
${ }^{1}$ Laboratory of Pathogenic Biology, Guangdong Medical College, Zhanjiang, Guangdong 524023; \\ ${ }^{2}$ Department of Cardiothoracic Surgery; ${ }^{3}$ Intensive Care Unit, Affiliated Hospital of Guangdong \\ Medical College, Zhanjiang, Guangdong 524000; ${ }^{4}$ Department of Experimental Medicine, \\ Taiping People's Hospital of Dongguan, Dongguan, Guangdong 523095, P.R. China
}

Received September 22, 2014; Accepted August 6, 2015

DOI: 10.3892/etm.2015.2851

\begin{abstract}
The association between antibiotic resistance and SHV-12 extended-spectrum $\beta$-lactamase (ESBL) in Enterobacter cloacae remains unknown. The aim of the present study was to investigate the prevalence of both chromosome- and plasmid-borne SHV-12 ESBL genes in Enterobacter cloacae. Transmission of the SHV-12 ESBL gene was explored, and the risk factors for antibiotic resistance in E. cloacae were analyzed. Polymerase chain reaction (PCR) results showed that 58 out of the 100 isolates carried the SHV-12 ESBL gene: $34.48 \%$ of them occurred in the chromosome, $48.28 \%$ were plasmid-borne and $17.24 \%$ appeared in both. Enterobacterial repetitive intergenic consensus-PCR tests detected 82 chromosomal genotypes. Conjugation assays showed that $70.00 \%$ of plasmid-borne SHV-12 ESBL genes were successfully transconjugated into E. coli C600 and that the antibiotic resistance phenotype of E. cloacae was partially $(84 \%)$ or completely $(10 \%)$ transferred. A significantly higher SHV-12 ESBL detection rate was found in patients with underlying conditions and/or complications compared with those without $(\mathrm{P}<0.05)$. The detection of SHV-12 ESBL-producing E. cloacae from vertical transmission varied significantly across clinical departments and age groups $(\mathrm{P}<0.05)$, with the highest rates in the intensive care unit and the group of patients aged $\geq 60$ years. The present results indicate that the location and transmission efficiency of SHV-12 ESBL are closely correlated with the antibiotic resistance of E. cloacae.
\end{abstract}

Correspondence to: Dr Zu-Guo Zhao, Laboratory of Pathogenic Biology, Guangdong Medical College, 2 Wenming Road (East), Zhanjiang, Guangdong 524023, P.R. China

E-mail: zuguo1224@163.com

Key words: Phenotype, Enterobacter cloacae, enterobacterial repetitive intergenic consensus-polymerase chain reaction, SHV-12, extended spectrum $\beta$-lactamases

\section{Introduction}

Over recent decades, the Enterobacter cloacae complex (consisting of Enterobacter cloacae, Enterobacter asburiae, Enterobacter hormaechei, Enterobacter kobei, Enterobacter ludwigii and Enterobacter nimipressuralis) has taken on clinical significance, with its species emerging as nosocomial pathogens, particularly in intensive care units (ICUs). E. cloacae is the most representative species of the E. cloacae complex (1). This species can cause severe opportunistic infections in hospital patients, including lower respiratory, urinary tract and wound infections, as well as hospital-acquired sepsis (2). The increasing prevalence of E. cloacae is due predominantly to a high level of resistance to antimicrobial agents. SHV-type extended-spectrum $\beta$-lactamases (ESBLs), encoded by the $b l a_{\mathrm{SHV}}$ gene confer significant resistance to $\beta$-lactam antibiotics (3). SHV-type ESBLs have $>140$ variants, and the SHV-12-type ESBL is one of the most prevalent types in Asia $(4,5)$.

SHV-12 ESBL can be located on the chromosome, a plasmid or both (6) and can be transmitted horizontally and/or vertically. The location of the SHV-12 ESBL gene and the pathway of transmission vary by region, hospital and time span $(7,8)$.

Bacteria continuously adjust gene expression in response to environmental changes. Currently, central venous catheters, malignant tumors, history of antibiotic usage and Pitt bacteremia score are regarded as the risk factors for bacterial infection (9); however, associated risk factors are distinct based on differences in hospital settings, practitioners, usage of medications and the condition of the patient, suggesting that additional external factors may be at play in the evolution of antibiotic resistance for E. cloacae (10-12).

Currently, the association between SHV-12 ESBL and the antibiotic resistance of E. cloacae has not been reported in the Guangdong region of China. In this study, therefore, the prevalence of E. cloacae and the correlation between the antibiotic resistance of E. cloacae and the prevalence status of SHV-12 ESBL were analyzed, a transmission model was delineated, and external factors that affect the location and transmission of SHV-12 ESBL were investigated. By 
analyzing the association between the SHV-12 ESBL gene and the antibiotic resistance of E. cloacae with the combined effect of both internal and external factors, the aim was to provide evidence for the proper usage of antibiotics to help control the spread of drug-resistant genes.

\section{Materials and methods}

Bacterial isolates. Unique isolates of E. cloacae $(n=100)$ were collected from randomly selected inpatients (62 men and 38 women) from the Affiliated Hospital of Guangdong Medical College (Zhanjiang, China) and the Taiping People's Hospital of Dongguan (Dongguan, China) between June 2012 and July 2013. All patients provided informed consent. Bacteria were identified using the BD Phoenix Automated Microbiology System (BD Pheonix ${ }^{\mathrm{TM}}$ 100; BD Biosciences, Franklin Lakes, NJ, USA) and the corresponding identification card. Escherichia coli ATCC 25922, E. coli C600 and SHV-12 ESBL-negative and -positive strains were from the Laboratory of Pathogenic Biology of Guangdong Medical College.

Antimicrobial susceptibility. Antimicrobial susceptibility testing was performed on 100 isolates by agar dilution, as recommended by the Clinical and Laboratory Standards Institute (13). The antibiotics were $\beta$-lactams [ampicillin (AM), cefazolin, cefuroxime (CXM), ceftazidime (CAZ), cefepime, cefoxitin (FOX), aztreonam (AZT), sulbactam + cefoperazone (SCF), tazobactam + piperacillin (TZP), imipenem (IMP), fluoroquinolone [ciprofloxacin (CIP) and levofloxacin (OFL)], aminoglycosides [amikacin (AMK) and gentamycin (GEN)] and a sulfonamide [sulfamethoxazole (SXT)]. All antibiotics were purchased from the National Institute for Food and Drug Control (Beijing, China)

Sequencing of SHV-12 ESBLs. The plasmid was eliminated using the variable-temperature-sodium dodecyl sulfate plasmid elimination method as described previously (14). Plasmid removal was verified using agarose gel electrophoresis. Chromosomal DNA was prepared using the FastPure ${ }^{\mathrm{TM}}$ DNA kit [Takara Biotechnology (Dalian) Co., Ltd., Dalian, China] and plasmid DNA was prepared using the Plasmid Mini kit (Qiagen, Hilden, Germany) following the manufacturers' instructions. The purified DNA was used as a template for PCR using an upstream primer pair, SHV-12-U (5'-GGTTATGCGTTATATTCGCC-3'), and a downstream primer pair, SHV-12-D (5'-TTAGCGTTGCCAGTGCTC-3'), which were synthesized in Sangon Biotech (Shanghai) Co., Ltd. (Shanghai, China). The desired polymerase chain reaction (PCR) product of the SHV-12 ESBL gene was $865 \mathrm{bp}$. The PCR product was purified using a PCR purification kit [Takara Biotechnology (Dalian) Co., Ltd.] and cloned into the pMDTM 18-T vector. Recombinant plasmids were transformed into E. coli DH5 $\alpha$ using T-A cloning; the transformants were selected using PCR and were then subjected to DNA sequencing. The PCR cycle conditions were as follows: Initial denaturation at $95^{\circ} \mathrm{C}$ for $5 \mathrm{~min}$; denaturation at $95^{\circ} \mathrm{C}$ for $1 \mathrm{~min}$, annealing at $52^{\circ} \mathrm{C}$ for $30 \mathrm{~min}$ and extension at $72^{\circ} \mathrm{C}$ for $1 \mathrm{~min}$, repeated for 30 cycles; final extension at $72^{\circ} \mathrm{C}$ for

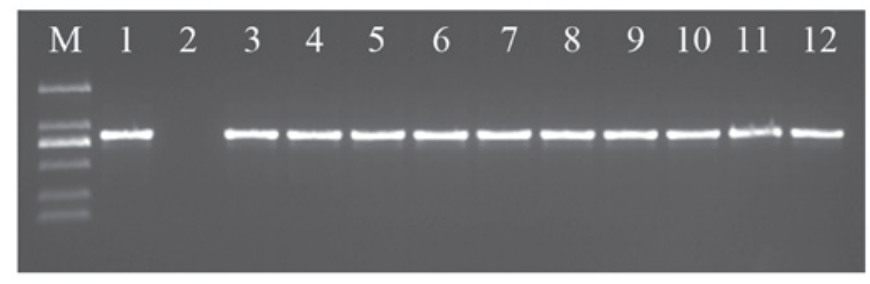

Figure 1.Polymerase chain reaction amplification of the SHV-12 extended-spectrum $\beta$-lactamase gene in experimental isolates. M, DNA ladder (from top to bottom: 2,000, 1,000, 750, 500, 250 and $100 \mathrm{bp}$ ); 1, positive control; 2, negative control; 3-12, experimental isolates.

$5 \mathrm{~min}$. The resulting sequences were aligned with available GenBank data using the Basic Local Alignment Search Tool (http://blast.ncbi.nlm.nih.gov/Blast.cgi).

Genotyping of enterobacteria. Enterobacterial repetitive intergenic consensus (ERIC)-PCR was used to genotype the clinical isolates. ERIC1R (5'-ATGTAAGCTCCTGGG GATTCAC-3') and ERIC2R (5'-AAGTAAGTGACTGGG GTGAGCG-3') primers that were complementary to ERIC sequences of E. cloacae genomic DNA were used for ERIC-PCR, which was performed as described by Stumpf et al (15).

Conjugation assay. Mueller-Hinton agar (National Institute for Food and Drug Control) containing rifampicin $(200 \mu \mathrm{g} / \mathrm{ml})$ and ceftriaxone $(5 \mu \mathrm{g} / \mathrm{ml})$ was used to select the E. cloacae. Rifampicin-resistant E. coli $\mathrm{C600}\left(\mathrm{LacZ}^{-} \mathrm{Nal}^{\mathrm{r}} \mathrm{F}^{-} \mathrm{Rif}^{\mathrm{r}}\right.$ ) was used as the recipient strain, and the ungrown C600 was used as the donor strain. E. coli transconjugants were selected on Mueller-Hinton agar plates containing rifampicin (200 $\mu \mathrm{g} / \mathrm{ml})$ and ceftriaxone $(5 \mathrm{mg} / \mathrm{l})$, and bacterial colonies with rifampicin and ceftriaxone-resistance were inoculated onto Eosin-Methylene blue agar plates (containing the same concentration of rifampicin and ceftriaxone). Colorless bacterial colonies on Eosin-Methylene blue agar plates were considered as transconjugants. PCR amplification of the SHV-12 ESBL gene was performed using plasmid DNA of the transconjugant as a template and C600 donor strain as a negative control.

Statistical analysis. An $\mathrm{RxC}$ contingency table for the $\chi^{2}$ test, $2 \times 2$ contingency table for the $\chi^{2}$ test and Fisher's exact probability were used to assess whether statistical difference could be found in the antibiotic resistance rates between the positive and negative isolates, as well as among the three gene locations for positive isolates.

SHV-12 ESBL-positive and -negative isolates were designated as groups 1 and 2, respectively. Group 3 consisted of E. cloacae Types A, B and C, as typed by ERIC-PCR, while group 4 consisted of other types. Group 5 consisted of isolates that tested positive in the conjugation assay, while group 6 consisted of isolates that tested negative. For the comparison between groups 1 and 2, and groups 3 and 4, variables in these groups with P-values $<0.1$ in univariate analyses were separately entered into a multiple logistic regression model to identify the independent risk for E. cloacae carrying SHV-12 ESBLs and vertical spread, respectively. Yates' $\chi^{2}$ 
Table I. Antibiotic resistance and SHV-12 ESBL.

Resistant isolates, n (\%)

\begin{tabular}{|c|c|c|c|c|c|}
\hline \multirow[b]{2}{*}{ Antibiotic } & \multicolumn{2}{|c|}{ Resistant isolates, $\mathrm{n}(\%)$} & \multirow[b]{2}{*}{$\chi^{2}$} & \multirow[b]{2}{*}{ P-value } & \multirow{2}{*}{$\begin{array}{c}\text { Total resistance } \\
\text { rate, } \%\end{array}$} \\
\hline & SHV-12-positive & SHV-12-negative & & & \\
\hline AM & $58(100)$ & $42(100)$ & & & 100 \\
\hline CEF & $58(100)$ & $42(100)$ & & & 100 \\
\hline CXM & $43(74)$ & $30(71)$ & 0.09 & $>0.05$ & 73 \\
\hline CAZ & $39(67)$ & $20(48)$ & 3.88 & $<0.05$ & 59 \\
\hline FEP & $18(31)$ & $10(24)$ & 1.59 & $>0.05$ & 28 \\
\hline FOX & $55(95)$ & $27(64)$ & 15.40 & $<0.05$ & 83 \\
\hline $\mathrm{TZP}$ & $8(14)$ & $3(7)$ & 1.10 & $>0.05$ & 11 \\
\hline SCF & $27(47)$ & $12(29)$ & 3.31 & $>0.05$ & 39 \\
\hline AZT & $37(57)$ & $14(24)$ & 9.04 & $<0.05$ & 51 \\
\hline IMP & $0(0)$ & $0(0)$ & 0.00 & & 0 \\
\hline CIP & $22(38)$ & $8(19)$ & 4.14 & $<0.05$ & 30 \\
\hline OFL & $24(41)$ & $18(43)$ & 0.02 & $>0.05$ & 42 \\
\hline AMK & $9(16)$ & $3(7)$ & 1.62 & $>0.05$ & 12 \\
\hline GEN & $24(41)$ & $9(21)$ & 4.39 & $<0.05$ & 33 \\
\hline SXT & $31(53)$ & $11(26)$ & 7.43 & $<0.05$ & 42 \\
\hline
\end{tabular}

SHV-12-positive, $n=58$; SHV-12-negative, $n=42$. ESBL, extended-spectrum $\beta$-lactamase; AM, ampicillin; CEF, cefazolin; CXM, cefuroxime; CAZ, ceftazidime; FEP, cefepime; FOX, cefoxitin; TZP, tazobactam + piperacillin; SCF, sulbactam + cefoperazone; AZT, aztreonam; IMP, imipenem; CIP, ciprofloxacin; OFL, levofloxacin; AMK, amikacin; GEN, gentamycin; SXT, sulfamethoxazole.

test or exact probability was used to analyze the difference between groups 5 and 6 . All comparisons were performed using SPSS 17 software (SPSS, Inc., Chicago, IL, USA). $\mathrm{P}<0.05$ was considered to indicate a statistically significant difference for all tests.

\section{Results and Discussion}

Association between the SHV-12 ESBL gene and the resistance of E. cloacae to antibiotics. The SHV-12 ESBL gene was detected in all 58 E. cloacae isolates expressing ESBLs (Fig. 1). This percentage is higher than that reported in France (16) and Taiwan (9), but lower than that in Tunisia (17). A total of $34.48 \%$ (20 out of 58 isolates) of the SHV-12 ESBL genes were located in the bacterial chromosome, $48.28 \%$ ( 28 out of 58 isolates) in plasmids and $17.24 \%$ (10 out of 58 isolates) in both (Tables I and II).

As shown in Table I, SHV-12 ESBL-positive E. cloacae isolates demonstrated significant differences in antibiotic resistance against $\beta$-lactam antibiotics (CAZ, FOX, AZT), fluoroquinolone antibiotics (CIP), aminoglycoside antibiotics (GEN) and sulfonamides (SXT) compared with SHV-12 ESBL-negative isolates $(\mathrm{P}<0.05)$. It is known that ESBL-expressing E. cloacae carry resistance against fluoroquinolone antibiotics (18). Additionally the highly prevalent class I integron contains antibiotic resistance genes, mainly for aminoglycoside antibiotics and trimethoprim $(19,20)$. Similar results have been reported in isolates from Korean hospitals; however, SHV-12 ESBL-positive and -negative isolates did not show significant differences in antibiotic resistance to the $\beta$-lactam antibiotics (21). Other mechanisms may, therefore, also contribute to $\beta$-lactam antibiotic resistance.

The AMK-resistance rate in the SHV-12 ESBL expression strains was found to be $16 \%$ in the present study, which is between that in Mexico (25\%) and Taiwan (0\%) $(22,23)$. The AM resistance rate, however, was $100 \%$, which is higher than that in Mexico (13\%) (22). The fact that the antibiotic-resistance rate of $E$. cloacae in the current region is different from that in other areas may derive from the difference in drug usage and disease type.

SHV-12 ESBL gene location affects antibiotic resistance. The present results showed that all three types of gene location of SHV-12 ESBL could be found in the Guangdong region: A total of $34.48 \%$ (20 out of 58 isolates) of the SHV-12 ESBL genes were located in the bacterial chromosome, $48.28 \%$ (28 out of 58 isolates) in plasmids and $17.24 \%$ (10 out of 58 isolates) in both (Table II). The proportion of each type of location of SHV-12 ESBL in E. cloacae was similar to that of SHV ESBLs in E. coli in India (24), but was different from the chromosomal location of SHV-12 ESBL in Klebsiella pneumoniae in Egypt (6), indicating that the gene location of SHV-12 ESBL may be distinct in different regions or different strains.

In the present study, it was found that the three types of gene locations exhibited significant differences in antibiotic resistance rates for CXM, CAZ, SCF, OFL, GEN and SXT (Table II). The resistance rate for CXM, for example, was higher in the E. cloacae isolates carrying the chromosomal SHV-12 ESBL gene (100\%) than that in isolates carrying both plasmid and chromosomal SHV-12 ESBL genes (60\%). 
The opposite was true for CAZ; however, certain antibiotics, such as TZP, were unaffected by the gene location of SHV-12 ESBL, indicating that the mechanism of antibiotic resistance in E. cloacae is complicated and may be compounded by both internal and external factors.

EPIC-PCR typing. A total of 100 E. cloacae isolates were divided into 82 different chromosomal gene types via ERIC-PCR. The isolates were divided into three groups: A, B and C. Type A (9 isolates) and type B (6 isolates) all tested positive for the SHV-12 ESBL gene. Type C isolates (of which there were 6) tested negative for the SHV-12 ESBL gene. The remaining 79 isolates belonged to an orphan clone (Figs. 2 and 3). Of type A, 6 isolates carried chromosome-coded SHV-12 ESBL, while 3 isolates carried both chromosomal and plasmid-coded SHV-12 ESBL. Of type B, 4 isolates carried the chromosomal-coded gene, 1 carried the plasmid-coded gene and 1 carried both. The differential location of the SHV-12 ESBL gene within and between different bacterial gene types indicated that E. cloacae carrying SHV-12 ESBL could be transmitted via both vertical and horizontal transmission.

The ERIC-PCR result showed that E. cloacae of the same gene type could be detected throughout different clinical departments, suggesting an inter-departmental spread of E. cloacae (data not shown). Vertical spread, even outbreaks of E. cloacae carrying SHV-12 ESBLs, has also been reported in various regions of the world $(7,17,25)$. In this study, type $C$ E. cloacae carrying no SHV-12 ESBL were also found to spread between different clinical departments, implying that other factors could also contribute to the spreading of antibiotic-resistant strains in hospital.

Transconjugation experiment. A total of 31 E. cloacae isolates carrying rifampicin $(200 \mu \mathrm{g} / \mathrm{ml})$ plus ceftriaxone $(5 \mathrm{mg} / \mathrm{l})$ resistance were selected for the transconjugation experiment. Of these isolates $52 \%$, carried the SHV-12 ESBL gene. In $94 \%$ of the cases, antibiotic resistance of E. cloacae could be transferred into $E$. coli, which indicated that plasmid-mediated resistance was common in E. cloacae and that antibiotic resistance genes could be easily spread via horizontal transmission. The positive rate of transconjugation in the Taiwan region, however, has been shown to be only $70 \%$ (26). In 84\% (26/31) of the transconjugation cases of the present study, only partial antibiotic resistance genes could be transferred, demonstrating that certain antibiotic resistance genes could not be transferred horizontally. It was also reported that antibiotic resistance genes in Aeromonas spp. could not be transferred horizontally. In $10 \%$ of the cases in the present study, E. coli acquired complete resistance from E. cloacae, which indicated that the antibiotic resistance plasmid in E. cloacae could mediate complete antibiotic resistance (Table III).

In $64 \%$ of the cases, the SHV-12 ESBL gene could be transconjugated successfully from E. cloacae to E. coli, which meant that horizontal transmission was a major method for the spread of SHV-12. A high prevalence of plasmid-encoded SHV-12 ESBL producers has been observed in the Sichuan province of China (27) and Tunisia (16).

Through the Yates' $\chi^{2}$ or Fisher's exact probability test, it was found that the factors that improved transconjugation 
Table III. Conjugation assays.

\begin{tabular}{lcccc}
\hline & & \multicolumn{3}{c}{ Transconjugants, $\mathrm{n}(\%)$} \\
\cline { 3 - 4 } SHV-12 location type (n) & $\begin{array}{c}\text { Positive } \\
\text { test, } \mathrm{n}(\%)\end{array}$ & $\begin{array}{c}\text { SHV-12 } \\
\text { positive }\end{array}$ & $\begin{array}{c}\text { Acquired } \\
\text { partial resistance }\end{array}$ & $\begin{array}{c}\text { Acquired } \\
\text { complete resistance }\end{array}$ \\
\hline Chromosome (6) & $5(83)$ & $0(0)$ & $5(83)$ & $1(17)$ \\
Plasmid (9) & $9(100)$ & $6(67)$ & $7(78)$ & $2(22)$ \\
Chromosome and plasmid (2) & $2(100)$ & $1(50)$ & $2(100)$ & $0(0)$ \\
SHV-12 negative (14) & $13(93)$ & $0(0)$ & $12(92)$ & $1(8)$ \\
Total (31) & $29(94)$ & $7(23)$ & $26(84)$ & $3(10)$ \\
\hline
\end{tabular}

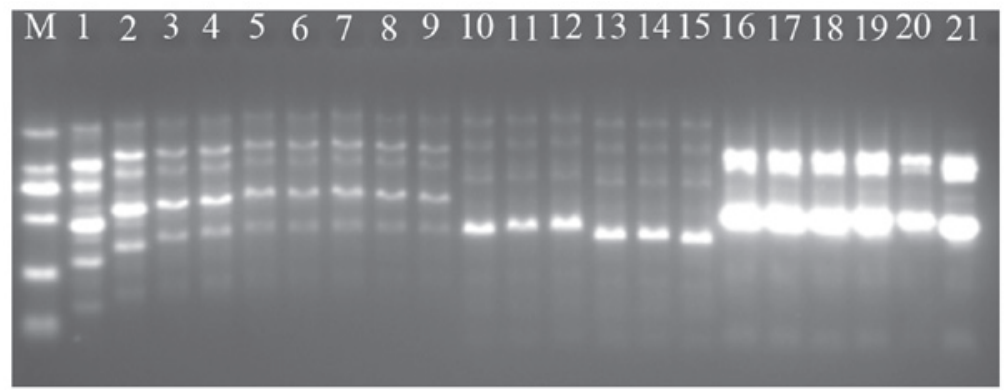

Figure 2. Enterobacterial repetitive intergenic consensus-polymerase chain reaction for type A, B and C isolates. M, DNA ladder (from top to bottom: 2,000, $1,000,750,500,250$ and $100 \mathrm{bp}) ; 1-9$, type A isolates; 10-15, type B isolates; 16-21, type C isolates.

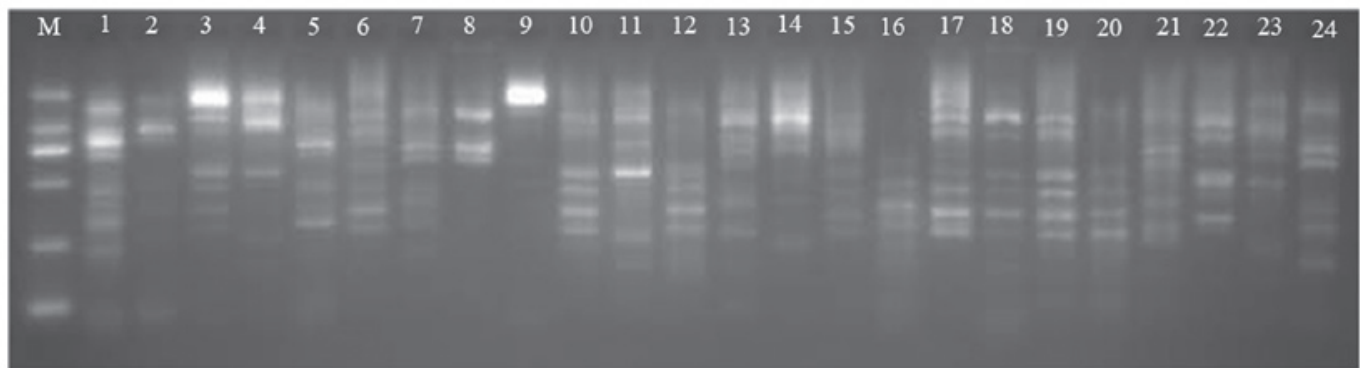

Figure 3. Enterobacterial repetitive intergenic consensus-polymerase chain reaction for different types of chromosomal DNA. The isolates with identical patterns of the same location of bands or same number of bands with different density were considered to be the same genotype; the isolates with differences in 1-2 bands were considered to be closely a related genotype; the isolates with differences in $>2$ bands were considered to be a different genotype. M, DNA ladder (from top to bottom: 2,000, 1,000, 750, 500, 250 and $100 \mathrm{bp}$ ); 1-24, experimental isolates.

rates in patients were male gender, use of antibiotics in the last 30 days, hospital stays lasting $>14$ days and Charlson comorbidity index $(\mathrm{CCI})>2(\mathrm{P}<0.05)$. This result also indicated that these factors could affect the horizontal transmission of antibiotic resistance in clinical niches.

Association between external factors and E. cloacae antibiotic resistance. The $E$. cloacae strains were isolated from 7 types of samples collected from 18 clinical departments (Table IV), which meant that E. cloacae could cause various infections. In the ICU and respiratory department, E. cloacae had the highest $(30 \%)$ and second highest $(11 \%)$ positive rates, respectively. In Taiwan, the ICU is also the most common department in which E. cloacae strains have been isolated (9). In the region analyzed in the present study, the majority of the E. cloacae strains were from the sputum; this is similar to the situation in Tunisia and southern Brazil (17), but different from France and Taiwan, where the urinary tract is the most common infection site for E. cloacae (28).

Respiratory tract infection caused by $E$. cloacae occurs in different age groups. Patients aged $\geq 60$ years had the highest E. cloacae infection rate $(54 \%)$, and male patients were more likely to be infected by E. cloacae than female patients (62 male vs. 38 female patients; male to female ratio, 1.63:1). A similar effect of age and gender on E. cloacae infection rate has also been reported in other regions of the world (16).

In total, $>50 \%$ of the patients infected with E. cloacae were undergoing invasive treatment, had underlying diseases and/or complications, had been taking antibiotics for $>30$ days, were hospitalized for $>14$ days or had a CCI 
Table IV. External factors and antibiotic resistance.

\begin{tabular}{|c|c|c|c|c|c|c|}
\hline \multirow[b]{2}{*}{ Factor } & \multicolumn{6}{|c|}{ Isolates, n (\%) } \\
\hline & $\begin{array}{l}\text { Group } 1 \\
(\mathrm{n}=58)\end{array}$ & $\begin{array}{l}\text { Group } 2 \\
(\mathrm{n}=42)\end{array}$ & $\begin{array}{c}\text { Group } 3 \\
(\mathrm{n}=21)\end{array}$ & $\begin{array}{l}\text { Group } 4 \\
(\mathrm{n}=79)\end{array}$ & $\begin{array}{c}\text { Group } 5 \\
(\mathrm{n}=72)\end{array}$ & $\begin{array}{c}\text { Group } 6 \\
(\mathrm{n}=3)\end{array}$ \\
\hline \multicolumn{7}{|l|}{ Source of isolates } \\
\hline Sputum & $28(48)$ & $21(50)$ & $16(76)$ & $33(42)$ & $35(78)$ & $3(100)$ \\
\hline Urine & $10(17)$ & $12(29)$ & $3(14)$ & $19(24)$ & $13(18)$ & $0(0)$ \\
\hline Other sources ${ }^{1}$ & $20(35)$ & $9(21)$ & $2(10)$ & $27(34)^{\mathrm{b}}$ & $24(33)$ & $0(0)$ \\
\hline \multicolumn{7}{|l|}{ Clinical department } \\
\hline Intensive Care Unit & $27(47)$ & $3(7)^{a}$ & $11(52)$ & $19(24)^{b}$ & $27(38)$ & $0(0)$ \\
\hline Respiratory Medicine & $6(10)$ & $5(12)$ & $3(14)$ & $8(10)$ & $8(11)$ & $0(0)$ \\
\hline Other departments ${ }^{2}$ & $25(43)$ & $34(81)^{\mathrm{a}}$ & $7(33)$ & $52(66)^{\mathrm{b}}$ & $37(51)$ & $3(100)$ \\
\hline \multicolumn{7}{|l|}{ Age in years } \\
\hline $1-14$ & $7(12)$ & $2(5)$ & $0(0)$ & $9(11)$ & $7(10)$ & $1(33)$ \\
\hline $15-59$ & $24(41)$ & $13(31)$ & $5(24)$ & $32(41)$ & $28(39)$ & $2(33)$ \\
\hline$\geq 60$ & $27(47)$ & $27(64)$ & $16(76)$ & $38(48)^{\mathrm{b}}$ & $37(51)$ & $0(0)$ \\
\hline \multicolumn{7}{|l|}{ Gender } \\
\hline Male & $40(69)$ & $22(52)$ & $11(52)$ & $51(65)$ & $50(69)$ & $0(0)$ \\
\hline Female & $18(31)$ & $20(48)$ & $10(48)$ & $28(35)$ & $22(31)$ & $3(100)$ \\
\hline \multicolumn{7}{|l|}{ Other factors } \\
\hline Invasive procedure & $44(76)$ & $20(48)^{\mathrm{a}}$ & $16(76)$ & $48(61)$ & $49(68)$ & $2(67)$ \\
\hline $\begin{array}{l}\text { Presence of any underlying illnesses } \\
\text { and/or comorbidities }\end{array}$ & $56(97)$ & $34(81)^{a}$ & $21(100)$ & $69(87)$ & $64(89)$ & $2(67)$ \\
\hline Use of antibiotics in the last 30 days & $53(91)$ & $39(93)$ & $21(100)$ & $71(90)$ & $67(93)$ & $0(0)^{\mathrm{c}}$ \\
\hline Hospitalization $>14$ days & $53(91)$ & $31(74)^{\mathrm{a}}$ & $21(100)$ & $63(80)$ & $60(83)$ & $0(0)^{\mathrm{c}}$ \\
\hline $\mathrm{CCI}>2$ & $51(88)$ & $29(69)^{\mathrm{a}}$ & $19(90)$ & $61(77)$ & $60(83)$ & $0(0)^{\mathrm{c}}$ \\
\hline Hospital patients & $57(98)$ & $42(100)$ & $21(100)$ & $77(97)$ & $71(99)$ & $3(100)$ \\
\hline Mortality & $5(9)$ & $0(0)$ & $4(19)$ & $1(5)$ & $4(6)$ & $0(0)$ \\
\hline
\end{tabular}

${ }^{\mathrm{a}} \mathrm{P}<0.05$, compared with group 1 ; ${ }^{\mathrm{b}} \mathrm{P}<0.05$, compared with group 2 ; ${ }^{\mathrm{c}} \mathrm{P}<0.05$, compared with group 5 . ${ }^{1}$ Other sources includes blood $(\mathrm{n}=13$ ), exudates $(n=5)$, pus $(n=4)$, bile $(n=4)$ and pleural fluid $(n=3) ;{ }^{2}$ Other departments includes the departments of Internal Hematology $(n=9)$, Neurology $(n=6)$, Urology $(n=5)$, Pediatrics $(n=5)$, Cardiothoracic Surgery $(n=5)$, Urological Surgery $(n=4)$, Orthopedic Surgery $(n=4)$, Hepatobiliary Surgery $(n=4)$, Neurosurgery $(n=3)$, Geriatrics $(n=3)$, Plastic Surgery $(n=2)$, Pediatric Surgery $(n=1)$ and Clinical Infectious Diseases $(n=1)$, as well as the Coronary Care Unit $(n=3)$ and section for outpatients $(n=1)$. CCI, Charlson comorbidity index.

$>2$, which further illustrated that infection with E. cloacae is closely associated with external factors; this is consistent with other investigations (10-12).

Notably, antibiotic abuse has been considered an essential reason for antibiotic resistance and the wide spread of antibiotic-resistant strains; however, no significant effect of antibiotic usage for $>30$ days was found in groups 1-4. A possible reason could be the 3 -year application of antibiotic usage policy in Guangdong, where the samples were collected. In this study, a higher positive rate of ESBLs was found compared with other regions of China. One possible explanation is that the antibiotic resistance gene is preserved in the strain for long periods of time and spread once it is captured by mobile genetic elements, such as integrons (29).

As analyzed by multiple logistic regressions, the risk factors for infection by SHV-12-producing E. cloacae were age, clinical department and having an underlying disease or complication $(\mathrm{P}<0.05)$. In a previous study, the risk factors for suffering bloodstream infections of E. cloacae carrying ESBLs were disease severity, category of healthcare-associated infection and prior use of antibiotics or a ventilator (23). This difference may be associated with the method of drug administration used by the doctors and the sample source.

E. cloacae isolated from the bile had the highest antibiotic resistance rate compared with those isolated from the other sources (data not shown). Although the positive rate for E. cloacae was low in the pus, secretions, bile and chest water, the majority of the E. cloacae detected were positive for SHV-12 ESBL, which is noteworthy for clinicians.

E. cloacae isolated from ICU samples had the highest positive rate for SHV-12 ESBLs. This may have been due to the fact that those patients in the ICU had an increased incidence of underlying diseases or complications. Additionally, ICU patients often have undergone prior stays in other departments or have used broad-spectrum antibiotics, which may increase the possibility of acquiring SHV-12 ESBLs for E. cloacae (28). 
Multiple logistic regression analysis results showed that the risk factors for vertical transmission were infection site, age and clinical department. The horizontal spread of SHV-12 ESBLs was the most common between E. cloacae strains separated from the sputum (76\%), the elderly (76\%) and ICU patients (52\%), which is consistent with the most common sample type, clinical department and patient age in this region. Horizontal transmission of E. cloacae was reported in an ICU in Croatia, and was common in respiratory tract infections and the elderly (30).

In conclusion, the expression pattern, gene location and transmission pathways of SHV-12 ESBL and other external factors have a close correlation with the antibiotic resistance of E. cloacae. To prevent the wide spread of SHV-12 ESBL, as well as outbreaks of multi-drug-resistant strains, we propose that more attention be given to the clinical investigation of SHV-12 ESBL-expressing E. cloacae to better monitor its spread and provide evidence for the proper usage of antibiotics.

\section{Acknowledgements}

The authors would like to acknowledge the financial support from the Science and Technology Key Projects Initiative of Zhanjiang City (grant no. 2012C3106022), the Special Fund for Science and Technology, Treasury Department of Zhanjiang City (grant no. 2013A01007), the General Projects of Guangdong Medical College (grant no. M2012005), the Science and Technological Program for Dongguan's Higher Education, Science and Research, and Health Care Institutions (grant no. 01310515000270), as well as the Medical Research Fund Project of Guangdong Province (grant no. A2015329).

\section{References}

1. Mezzatesta ML, Gona F and Stefani S: Enterobacter cloacae complex: Clinical impact and emerging antibiotic resistance. Future Microbiol 7: 887-902, 2012.

2. Xiao YH, Shen P, Wei ZQ, Chen YB, Kong HS, Yang Q, Zhang WL, Chen X and Li LJ: Mohnarin report of 2011: Monitoring of bacterial resistance in China. Zhong Hua Yi Yuan Gan Ran Xue Za Zhi 22: 4946-4952, 2012 (In Chinese).

3. Bradford PA: Extended-spectrum beta-lactamases in the 21st century: Characterization, epidemiology and detection of this important resistance threat. Clin Microbiol Rev 14: 933-951, 2001.

4. Hawkey PM: Prevalence and clonality of extended-spectrum beta-lactamases in Asia. Clin Microbiol Infect 14 (Suppl 1): $159-165,2008$

5. Chia JH, Chu C, Su LH, Chiu CH, Kuo AJ, Sun CF and Wu TL: Development of a multiplex PCR and SHV melting-curve mutation detection system for detection of some SHV and CTX-M beta-lactamases of Escherichia coli, Klebsiella pneumoniae and Enterobacter cloacae in Taiwan. J Clin Microbiol 43: 4486-4491, 2005.

6. Newire EA, Ahmed SF, House B, Valiente E and Pimentel G: Detection of new SHV-12, SHV-5 and SHV-2a variants of extended spectrum beta-lactamase in Klebsiella pneumoniae in Egypt. Ann Clin Microbiol Antimicrob 12: 16, 2013.

7. Juhász E, Jánvári L, Tóth A, Damjanova I, Nobilis A and Kristóf K: Emergence of VIM-4- and SHV-12-producing Enterobacter cloacae in a neonatal intensive care unit. Int J Med Microbiol 302: 257-260, 2012.

8. Tansawai U, Boonkerd N, Polwichai P, Dejsirilert S and Niumsup PR: SHV-12 extended spectrum beta-lactamase associated with high-level ceftazidime resistance in Enterobacter cloacae isolated from Thailand. Southeast Asian J Trop Med Public Health 40: 148-154, 2009.
9. Lee $\mathrm{CH}$, Su LH, Li CC, Chien CC, Tang YF and Liu JW: Microbiologic and clinical implications of bacteremia due to extended-spectrum-beta-lactamase-producing Klebsiella pneumoniae with or without plasmid-mediated AmpC beta-lactamase DHA-1. Antimicrob Agents Chemother 54: 5395-5398, 2010.

10. Lee CC, Lee NY, Yan JJ, Lee HC, Chen PL, Chang CM, Wu CJ, Ko NY, Wang LR, Chi CH and Ko WC: Bacteremia due to extended spectrum-beta-lactamase-producing Enterobacter cloacae: Role of carbapenem therapy. Antimicrob Agents Chemother 54: 3551-3556, 2010.

11. Liu CP, Wang NY, Lee CM, Weng LC, Tseng HK, Liu CW, Chiang CS and Huang FY: Nosocomial and community-acquired Enterobacter cloacae bloodstream infection: Risk factors for and prevalence of SHV-12 in multiresistant isolates in a medical centre. J Hosp Infect 58: 63-77, 2004

12. Rodríguez-Baño J, Miró E, Villar M, Coelho A, Gozalo M, Borrell N, Bou G, Conejo MC, Pomar V, Aracil B, et al: Colonisation and infection due to Enterobacteriaceae producing plasmid-mediated AmpC $\beta$-lactamases. J Infect 64: 176-183, 2012.

13. CLSI: Performance Standards for Antimicrobial Susceptibility Testing; Twenty-Second Informational Supplement. CLSI document M100-S22. Clinical and Laboratory Standards Institute, Wayne, PA, 2013

14. Ni YX: Plasmid annihilation. In: Basic and Clinical Microbial Drug Resistance. Zhang ZR, Xia MY and Ni YX (eds.). People's Medical Publishing House, Beijing, pp240-242, 2006.

15. Stumpf AN, Roggenkamp A and Hoffmann H: Specificity of Enterobacterial repetitive intergenic consensus and repetitive extragenic palindromic polymerase chain reaction for the detection of clonality within the Enterobacter cloacae complex. Diagn Microbiol Infect Dis 53: 9-16, 2005.

16. Biendo M, Manoliu C, Laurans G, Castelain S, Canarelli B, Thomas D, Hamdad F, Rousseau F and Eb F: Molecular typing and characterization of extended-spectrum TEM, SHV and CTX-M beta-lactamases in clinical isolates of Enterobacter cloacae. Res Microbiol 159: 590-594, 2008.

17. Lahlaoui H, Anis BH, Mohamed $\mathrm{K}$ and Mohamed BM: Emergence of SHV-12 extended spectrum beta-lactamase among clinical isolates of Enterobacter cloacae in Tunisia. Microb Pathog 53: 64-65, 2012.

18. Miró E, Segura C, Navarro F, Sorlí L, Coll P, Horcajada JP, Alvarez-Lerma $F$ and Salvadó $\mathrm{M}$ : Spread of plasmids containing the bla(VIM-1) and bla(CTX-M) genes and the qnr determinant in Enterobacter cloacae, Klebsiella pneumoniae and Klebsiella oxytoca isolates. J Antimicrob Chemother 65: 661-665, 2010.

19. Liu J, Li GM, Zhao Y, Hu XH, Yang WQ and Yang JR: Study on the resistance genes of avriable region of class I integron in Enterobacter cloacae. Zhong Guo Kang Sheng Su Za Zhi 36: 543-547, 2011 (In Chinese).

20. Liu J, Li GM, Zhao Y, Hu XH, Yang WQ and Yang JR: Correlation among integron positioning, ESBL-production and resistance in Enterobacter cloacae. Guang Dong Yi Xue 32: 195-198, 2011 (In Chinese).

21. Ko KS, Lee MY, Song JH, Lee H, Jung DS, Jung SI, Kim SW, Chang HH, Yeom JS, Kim YS, et al: Prevalence and characterization of extended-spectrum beta-lactamase-producing Enterobacteriaceae isolated in Korean hospitals. Diagn Microbiol Infect Dis 61: 453-459, 2008.

22. Garza-González E, Mendoza Ibarra SI, Llaca-Díaz JM and Gonzalez GM: Molecular characterization and antimicrobial susceptibility of extended-spectrum $\{$ beta\}-lactamase-producing Enterobacteriaceae isolates at a tertiary-care centre in Monterrey, Mexico. J Med Microbiol 60: 84-90, 2011.

23. Chen $\mathrm{CH}$ and Huang CC: Risk factor analysis for extended-spectrum $\beta$-lactamase-producing Enterobacter cloacae bloodstream infections in central Taiwan. BMC Infect Dis 13: 417, 2013

24. Sharma J, Sharma M and Ray P: Detection of TEM \& SHV genes in Escherichia coli \& Klebsiella pneumoniae isolates in a tertiary care hospital from India. Indian J Med Res 132: 332-336, 2010.

25. Nogueira Kda S, Paganini MC, Conte A, Cogo LL, Taborda de Messias Reason I, da Silva MJ and Dalla-Costa LM: Emergence of extended-spectrum $\beta$-lactamase producing Enterobacter spp. in patients with bacteremia in a tertiary hospital in southern Brazil. Enferm Infecc Microbiol Clin 32: 87-92, 2014. 
26. Yan JJ, Ko WC, Chuang CL and Wu JJ: Metallo-beta-lactamas e-producing Enterobacteriaceae isolates in a university hospital in Taiwan: Prevalence of IMP-8 in Enterobacter cloacae and first identification of VIM-2 in Citrobacter freundii. J Antimicrob Chemother 50: 503-511, 2002.

27. Liu G, Ling BD, Zeng Y, Lin L, Xie YE and Lei J: Molecular characterization of extended-spectrum beta-lactamases produced by clinical isolates of Enterobacter cloacae from a teaching hospital in China. Jpn J Infect Dis 61: 286-289, 2008.

28. Biendo M, Manoliu C, Laurans G, Castelain S, Canarelli B, Thomas D, Hamdad F, Rousseau F and Eb F: Molecular typing and characterization of extended-spectrum TEM, SHV and CTX-M beta-lactamases in clinical isolates of Enterobacter cloacae. Res Microbiol 159: 590-594, 2008.
29. Machado E, Ferreira J, Novais A, Peixe L, Cantón R, Baquero $\mathrm{F}$ and Coque TM: Preservation of integron types among Enterobacteriaceae producing extended-spectrum beta-lactamases in a Spanish hospital over a 15-year period (1988 to 2003). Antimicrob Agents Chemother 51: 2201-2204, 2007.

30. Novak A, Goic-Barisic I, Andrasevic AT, Butic I, Radic M, Jelic M, Rubic Z and Tonkic M: Monoclonal outbreak of VIM-1-carbapenemase-producing Enterobacter cloacae in intensive care unit, University Hospital Centre Split, Croatia. Microb Drug Resist 20: 399-403, 2014. 